\title{
Reducing operative morbidity among female patients combining laparoscopic hysterectomy and laparoscopic ventral hernia mesh repair procedures: a single centre 14 years experiences
}

\author{
Priti Agrawal $^{1 *}$, Rishi Kumar Agrawal' ${ }^{2}$ Jyotirmay Chandrakar ${ }^{3}$
}

\begin{abstract}
${ }^{1}$ Department of Obstetrics, Gynecology and Infertility, ${ }^{2}$ Department of General and Laproscopic surgery, ${ }^{3}$ Department of Anesthesia, Aarogya Hospital and Test tube Baby Centre, Raipur, Chhattisgarh, India
\end{abstract}

Received: 12 May 2021

Accepted: 04 June 2021

*Correspondence:

Dr. Priti Agrawal,

E-mail: drpritiagrawal15@gmail.com

Copyright: (C) the author(s), publisher and licensee Medip Academy. This is an open-access article distributed under the terms of the Creative Commons Attribution Non-Commercial License, which permits unrestricted non-commercial use, distribution, and reproduction in any medium, provided the original work is properly cited.

\begin{abstract}
Background: During laparoscopic ventral hernia repair (LVHR) mesh is used and so this procedure is not combined with any other major surgery, due to the risk of mesh infection. We did laparoscopic hysterectomy (LH) with LVHR in our study group and found it to be safe procedure with excellent patient recovery and satisfaction rates. Aims and objectives of the study was to assess the short- and long-term clinical outcomes of doing LH and LVHR simultaneously. The primary objectives were to evaluate the intraoperative and post-operative complications, mesh infection rates, hernia recurrence rates and patient satisfaction rates for at least 4 years.

Methods: This prospective study was conducted at Aarogya Hospital and test tube centre from 1st January 2007 to 31 st December 2016 and follow up completed by 31st December 2020. Total 100 women were included, willing for LH and LVHR simultaneously irrespective of the size of uterus and hernia defect size up to $7 \mathrm{cms}$.

Results: Maximum number of patients $65 \%$ were in the age group of $45-55$ years. $70 \%$ patients had previous surgeries commonest being LSCS in $46 \%$ cases. Hernia defect size was between $3-5 \mathrm{~cm}$ in length and width in $70 \%$ cases, requiring dual mesh fixation in $68 \%$ cases of size $15 \times 15 \mathrm{cms}$. Our recurrence rate for hernia was nil, $98 \%$ cases were highly satisfied with the surgical outcomes by the end of 4 years follow-up.

Conclusions: We emphasize that LH can be easily done with LVHR in combination reducing operative morbidity.
\end{abstract}

Keywords: Dual mesh (Proceed, Symbotex), Incisional hernia, Laparoscopic hysterectomy, Laparoscopic ventral hernia repair, Umbilical hernia

\section{INTRODUCTION}

Caesarean section (CS) is the most frequently performed procedure on women all over the world. Ventral hernias continue to be one of the most prevalent complications after abdominal surgery, pose significant medical issues and are associated with an economic burden and adverse quality of life. ${ }^{1,2}$ Hysterectomy is the second most frequently performed procedure on women with an incidence of $6 \%$ among married woman between the age of $30-49$ years. ${ }^{3} \mathrm{CS}$ rates are on rising trend and thereby the incidence of incisional hernias. In the last decade the wide used of laparoscopy for hysterectomy and ventral hernia repairs has led to shortened hospital stays, decreased pain, faster recovery times, decreased wound morbidity and lower hernia recurrence rates. During laparoscopic ventral hernia repair (LVHR) mesh is used and so this procedure is not combined with any other major surgery, due to the risk of mesh infection. The most important concern of mesh infection is preventable by means of selection of mesh material, maintain sterility of prosthesis and operating setup, proper disinfection and 
sterilization of scopes and adequate antibiotic coverage. We did laparoscopic hysterectomy (LH) with LVHR in our study group and found it to be safe procedure with excellent patient recovery and satisfaction rates. Aims and objectives of the study was to assess the short- and longterm clinical outcomes of doing LH and LVHR simultaneously. The primary objectives were to evaluate the intraoperative and post-operative complications, mesh infection rates, hernia recurrence rates and patient satisfaction rates for at least 4 years. Secondary objectives were assessment of surgical technique, types of mesh fixation technique, operative time, length of hospital stay, pain assessment, quality of life improvement, menopausal symptoms and requirement of hormone replacement therapy.

\section{METHODS}

This prospective study was conducted at Aarogya Hospital and test tube centre from 1st January 2007 to 31st December 2016 and follow up completed by 31st December 2020. The study protocol was approved by institutional review board and ethics committee. Informed written consent was obtained from all patients before opting for the surgical procedure. Total 100 women were included.

\section{Inclusion criteria}

All indicated cases willing for LH and LVHR simultaneously irrespective of the size of uterus and hernia defect size up to $7 \mathrm{cms}$ were included in the study.

\section{Exclusion criteria}

Any investigation like ultrasonography, CT scan, MRI or $\mathrm{D}$ and $\mathrm{C}$ reports were suspicious of uterine, ovarian or cervical malignancy. Any uterine specimen which would require electromechanical morcellation, chronic pelvic inflammatory diseases, tubo-ovarian abscess, grade IV endometriosis. Hernia defect size $>7 \mathrm{cms}$. American society of Anaesthesiologists (ASA) grade IV patients. Strangulated hernias, emergency surgeries, recurrence of hernia cases either with suture repair or mesh placement in the index surgery, associated problems like acute appendicitis, cholecystitis, ileitis, colitis, suspected abdominal tuberculosis, patients not willing for long term follow up, patient on immunosuppressants, corticosteroids, history of smoking or tobacco chewing, chronic obstructive pulmonary disease, morbid obesity were excluded from the study.

A complete preoperative evaluation was done prior to surgical intervention. Coexisting conditions like severe anaemia, chronic cough, hypertension and diabetes mellitus were controlled. Haemoglobin status, colposcopy, cervical cytology endometrial biopsy and CT scan reports were evaluated thoroughly prophylactic single dose antibiotic was given to all cases 30 minutes prior to surgery and continued till 4th postoperative day. All cases were done under general anaesthesia and in lithotomy position. Carbon dioxide pneumoperitoneum was created up to 12 $\mathrm{mm}$ of mercury using veress needle introduced through Palmer's point. $10 \mathrm{~mm}$ port was made and $10 \mathrm{~mm}$ telescope introduced through Palmers point. Two accessory $5 \mathrm{~mm}$ ports were made just below xiphirterum and on left lumbar wall in anterior axillary line under direct visualization for LVHR. Adhesions to the anterior abdominal wall surrounding the hernia were lysed and reduction of hernial contents was done, leaving hernia sac in situ.

LH was done with standard 4 ports using $5 \mathrm{~mm}$ telescope supraumbilically and three accessory $5 \mathrm{~mm}$ ports. Ligasure vessel sealer system was used for LH. No sutures or clips were used for LH leaving no foreign material on coagulated stumps. Specimen was removed vaginally. Vault was closed vaginally with vicryl no-1 on needle. This reduced operating time and sutures became extraperitoneal. After completion of $\mathrm{LH}$, the position of the patient was made supine. LH ports (all $5 \mathrm{~mm}$ ) closed with monocryl sutures. Abdominal wall was now again painted and drapped. Initial $10 \mathrm{~mm}$ and $5 \mathrm{~mm}$ accessory ports for LVHR kept in situ Surgeons rescrubbed.

After completion of the dissection the hernia defect was measured and an appropriately sized prosthetic mesh was chosen to overlap all margins of the defect by at least 3-5 cms. Dual mesh (Proceed, Symbotex) of appropriate size was then opened. A minimum of 4 prolene sutures were placed on mesh (proceed). The mesh was then introduced through the $10 \mathrm{~mm}$ port. The hernial defect was closed with either prolene or PDS no -1 using suture passer. After proper positioning of the mesh, a suture passer was used to pull the trans fascial sutures through separate incisions and tied with the knots buried in subcutaneous tissues (In Symbotex mesh sutures are prepositioned). The circumference of the mesh was then tacked to posterior fascia in double crown method using titanium non absorbable spiral tacks (protack).

At the completion of mesh placement, the bowel was examined for possible iatrogenic injury. The omentum and vault were observed for haemostasis. Omentum was spread between mesh and bowels. Then the pneumoperitoneum was released. The skin incisions were closed with absorbable sutures. $10 \mathrm{~mm}$ port was closed with port closure needle using vicryl no. 2-0 suture. No drains were kept. Compression dressing was done over hernia site and abdominal binder was given to all patients to prevent seroma formation.

\section{Follow up}

Patients were seen in OPD at regular intervals of one week, one month 3 months, six month and then yearly follow up for 4 years. At each visit, a full examination and ultrasonography was done to see signs of recurrence and mesh displacement. Patients were asked to fill questioner on patient satisfaction, pain, menopausal symptoms like hot flushes, anxiety, urinary and defecatory problems and 
quality of life improvement. Patients having menopausal symptoms were given hormone replacement therapy with either tibolone or conjugated equine oestrogens. Calcium $1000 \mathrm{mg}$ daily orally was given to all patients. Data from each visit were documented in the hospital's electronic medical record. If patient was unable to visit hospital then telephone calls were made and follow up recorded.

The Hospital Management System (HMS) version 2.0 software was used for record maintenance and statistical analysis. Categorical variables are presented as frequencies and percentage of the recorded entries. Pain was assessed at intervals during the study using a visual analogue scale (VAS) with score of $0-10,(0=$ no pain, 10=unbearable pain,) 0-4 mild pain, 5-7 moderate pain, 8-
10 severe pain. Single dose analgesic was given to all patients after 8 hours of surgery (Diclofenac). Further analgesics were added as per patient's pain assessment and pain relief.

\section{RESULTS}

Maximum number of patients $65 \%$ were in the age group of $45-55$ years. $20 \%$ were overweight and $20 \%$ were obese. $96 \%$ patients were multiparous. $70 \%$ patients had previous surgeries commonest being LSCS in $46 \%$ cases. Midline vertical incisions lead to incisional hernia in $96 \%$ cases. Chronic hypertension was seen in $40 \%$ cases (Table 1 ).

Table 1: Patient profile.

\begin{tabular}{|c|c|c|}
\hline Variables & Number & Percentage \\
\hline \multicolumn{3}{|l|}{ Age (in years) } \\
\hline $35-45$ & 24 & 24 \\
\hline $45-55$ & 65 & 65 \\
\hline $55-65$ & 08 & 08 \\
\hline $65-75$ & 03 & 03 \\
\hline \multicolumn{3}{|l|}{ BMI $\left(\mathrm{Kg} / \mathbf{m t}^{2}\right)$} \\
\hline $20-25$ & 60 & 60 \\
\hline $25-30$ & 20 & 20 \\
\hline $30-35$ & 12 & 12 \\
\hline $35-40$ & 08 & 08 \\
\hline$>40$ & Nil & Nil \\
\hline \multicolumn{3}{|l|}{ Parity } \\
\hline 1 & 04 & 04 \\
\hline 2 & 65 & 65 \\
\hline 3 & 15 & 15 \\
\hline$>4$ & 16 & 16 \\
\hline \multicolumn{3}{|c|}{ History of previous surgeries ( 70 cases) } \\
\hline \multicolumn{3}{|c|}{ LSCS } \\
\hline One & 05 & 05 \\
\hline Two & 33 & 33 \\
\hline Three & 08 & 08 \\
\hline Tubectomy & 02 & 02 \\
\hline \multicolumn{3}{|l|}{ Laparotomy } \\
\hline Ectopic pregnancy & 03 & 03 \\
\hline Intestinal perforation & 04 & 04 \\
\hline Intestinal obstruction & 05 & 05 \\
\hline Appendectomy & 03 & 03 \\
\hline Ovarian cystectomy & 05 & 05 \\
\hline Laparoscopic port site hernia & 02 & 02 \\
\hline \multicolumn{3}{|l|}{ Type of incision } \\
\hline Midline vertical & 96 & 96 \\
\hline Pfannenstiel & 02 & 02 \\
\hline \multicolumn{3}{|c|}{ Associated medical disorders-62 } \\
\hline Hypertension & 40 & 40 \\
\hline Diabetes mellitus & 15 & 15 \\
\hline Bronchial Asthma & 03 & 03 \\
\hline Sickle cell anaemia & 02 & 02 \\
\hline On anticoagulants & 02 & 02 \\
\hline
\end{tabular}

Continued. 


\begin{tabular}{|c|c|c|}
\hline Variables & Number & Percentage \\
\hline \multicolumn{3}{|c|}{ American society of Anesthelogists (ASA) classification } \\
\hline Class I & 55 & 55 \\
\hline Class II & 43 & 43 \\
\hline Class III & 02 & 02 \\
\hline Class IV / V & Nil & Nil \\
\hline
\end{tabular}

Table 2: Chief presenting complaints and LH details $(n=100)$.

\begin{tabular}{|c|c|c|}
\hline Chief complaints & Number & Percentage \\
\hline Menorrhagia & 80 & 80 \\
\hline Abdominal swelling & 100 & 100 \\
\hline Chronic abdomen pain & 85 & 85 \\
\hline Severe dysmenorrhea & 35 & 35 \\
\hline Difficulty in urination and defecation & 10 & 10 \\
\hline Hernia reducible by taxis & 18 & 18 \\
\hline Dragging sensation & 35 & 35 \\
\hline \multicolumn{3}{|l|}{ Indications for hysterectomy } \\
\hline Fibroid uterus & 62 & 62 \\
\hline DUB & 26 & 26 \\
\hline Adenomyosis & 12 & 12 \\
\hline \multicolumn{3}{|l|}{ Relevant ultrasonographic findings } \\
\hline \multicolumn{3}{|l|}{ Uterine volume (in cu.cm) } \\
\hline $50-100$ & 26 & 26 \\
\hline $100-150$ & 24 & 24 \\
\hline $150-200$ & 20 & 20 \\
\hline $200-250$ & 15 & 15 \\
\hline$>250$ & 15 & 15 \\
\hline \multicolumn{3}{|l|}{ Ovarian status } \\
\hline Bilateral normal ovaries & 75 & 75 \\
\hline Bilateral atrophic ovaries & 15 & 15 \\
\hline Unilateral simple ovarian cyst $>5 \mathrm{~cm}$ & 08 & 08 \\
\hline \multicolumn{3}{|l|}{ Types of LH } \\
\hline LH with bilateral salpingectomy & 100 & 100 \\
\hline LH with bilateral oophorectomy & 15 & 15 \\
\hline LH with unilateral oophorectomy & 08 & 08 \\
\hline
\end{tabular}

Table 3: Types of ventral hernia, hernia defect size and types of mesh used.

\begin{tabular}{|lll|}
\hline N=100 & Number & Percentage \\
\hline Primary & 30 & 30 \\
\hline Incisional & 70 & 70 \\
\hline Post laparotomy & 68 & 68 \\
\hline Post laparoscopy & 02 & 02 \\
\hline Location of primary hernias & & \\
\hline Umbilical / Supraumbilical & 25 & 25 \\
\hline Epigastric & 05 & 05 \\
\hline Location for incisional hernia & & \\
\hline Epigastric & 04 & 04 \\
\hline Periumbilical & 02 & 02 \\
\hline Sub umbilical & 60 & 60 \\
\hline Suprapubic & 04 & 04 \\
\hline Hernia defect size & & \\
\hline Length & & 20 \\
\hline$<3 \mathrm{~cm}$ & 20 & 70 \\
\hline $3-5 \mathrm{~cm}$ & 70 & \\
\hline
\end{tabular}




\begin{tabular}{|lll|}
\hline $\mathbf{N}=\mathbf{1 0 0}$ & Number & Percentage \\
\hline $5-7 \mathrm{~cm}$ & 10 & 10 \\
\hline Width & & 20 \\
\hline$<3 \mathrm{~cm}$ & 20 & 70 \\
\hline $3-5 \mathrm{~cm}$ & 70 & 10 \\
\hline $5-7 \mathrm{~cm}$ & 10 & \\
\hline Types of mesh used & & 98 \\
\hline Dual mesh & & 02 \\
\hline (Proceed, Symbotex) & 98 & 02 \\
\hline Polypropylene Mesh & 02 & \\
\hline
\end{tabular}

Table 4: Intraoperative details.

\begin{tabular}{|c|c|c|c|}
\hline \multicolumn{2}{|c|}{ Surgical times (in minutes) } & Average & Range \\
\hline \multicolumn{2}{|c|}{ Laparoscopic hysterectomy } & 55 & $45-65$ \\
\hline \multicolumn{2}{|c|}{ Laparoscopic adhesiolysis } & 15 & $10-20$ \\
\hline \multicolumn{2}{|c|}{ Laparoscopic hernioplasty } & 40 & $30-50$ \\
\hline \multicolumn{2}{|c|}{ Total operating time } & 110 & $90-140$ \\
\hline \multicolumn{4}{|c|}{ Type and size of mesh } \\
\hline Type & Size & Number & Percentage \\
\hline $\begin{array}{l}\text { Dual mesh (size } \\
\text { in } \mathrm{cms} \text { ) }\end{array}$ & $12 \times 15$ & 20 & 20 \\
\hline \multirow[t]{2}{*}{$\begin{array}{l}\text { (Proceed, } \\
\text { Symbotex) }\end{array}$} & $15 \times 15$ & 68 & 68 \\
\hline & $20 \times 15$ & 10 & 10 \\
\hline $\begin{array}{l}\text { Polypropylene } \\
\text { mesh }\end{array}$ & $15 \times 15$ & 02 & 02 \\
\hline \multicolumn{2}{|c|}{ Mean blood loss (in ml) } & Number & Percentage \\
\hline \multicolumn{2}{|c|}{$20-30$} & 80 & 80 \\
\hline \multicolumn{2}{|l|}{$30-40$} & 10 & 10 \\
\hline \multicolumn{2}{|l|}{$40-50$} & 10 & 10 \\
\hline \multicolumn{2}{|c|}{$\begin{array}{l}\text { Complications during } \\
\text { surgeries }\end{array}$} & Nil & Nil \\
\hline \multicolumn{2}{|c|}{$\begin{array}{l}\text { Haemorrhage, ureteric, } \\
\text { bowel or bladder injury }\end{array}$} & Nil & Nil \\
\hline \multicolumn{2}{|c|}{ Conversion to Laparotomy } & Nil & Nil \\
\hline \multicolumn{2}{|c|}{ Anaesthesia complications } & Nil & Nil \\
\hline
\end{tabular}

Menorrhagia was the commonest menstrual complaint in $80 \%$ cases and hysterectomy was done for fibroid uterus in $62 \%$ cases. $100 \%$ cases found hernia because of appearance of abdominal swelling (Table 2).

Primary ventral hernias were umbilical or supraumblical in $25 \%$ cases. Hernia defect size was between $3-5 \mathrm{~cm}$ in length and width in $70 \%$ cases (Table 3) requiring dual mesh fixation in $68 \%$ cases of size $15 \times 15 \mathrm{cms}$ (Table 4 ).
$55 \%$ cases had moderate pain post operatively and $80 \%$ cases were discharged within 48 hours. Mild seroma formation occurred in 50\% cases (Table 5).

Our recurrence rate for hernia was nil, $98 \%$ cases were highly satisfied with the surgical outcomes by the end of 4 years follow-up. Menopausal symptoms requiring hormone replacement therapy occurred in $35 \%$ cases (Table 6).

Table 5: Postoperative details $(n=100)$.

\begin{tabular}{|lll|}
\hline Abdominal pain & $2^{\text {nd }}$ POD & $\mathbf{7}^{\text {th }}$ POD \\
\hline Mild & 10 & 85 \\
\hline Moderate & 55 & 15 \\
\hline Severe & 35 & Nil \\
\hline Pyrexia & Nil & Nil \\
\hline Post-operative ileus & 02 & Nil \\
\hline Nausea and vomiting & 25 & Nil \\
\hline $\begin{array}{l}\text { Mild vaginal bleeding and } \\
\text { discharge }\end{array}$ & Nil & 25 \\
\hline Rexplorations & Nil & Nil \\
\hline Pnemonitis & Nil & Nil \\
\hline Venous thrombosis & Nil & Nil \\
\hline Length of hospital stay & Number & Percentage \\
\hline Up to 2days & 80 & 80 \\
\hline 2-4 days & 20 & 20 \\
\hline SEROMA formation & Number & Percentage \\
\hline Mild & 50 & 50 \\
\hline Moderate & 10 & 10 \\
\hline Severe & Nil & Nil \\
\hline Port site infection & 02 & 02 \\
\hline Readmission & Nil & Nil \\
\hline
\end{tabular}

Table 6: Follow up details.

\begin{tabular}{|lllllll|}
\hline & $\mathbf{6}$ month & \multicolumn{3}{c|}{ 1 year } & \multicolumn{2}{c|}{ year } \\
\hline Pain in abdomen Number & $\mathbf{\%}$ & Number & $\mathbf{\%}$ & Number & $\mathbf{\%}$ & Number \\
\hline No pain & Nil & Nil & 60 & 60 & & \\
\hline Mild pain & 60 & 60 & 38 & 38 & Nil & Nil \\
\hline Moderate pain & 35 & 35 & 02 & 02 & Nil & Nil \\
\hline Severe pain & 05 & 05 & Nil & Nil & Nil & Nil \\
\hline
\end{tabular}

Continued. 


\begin{tabular}{|c|c|c|c|c|c|c|}
\hline & \multicolumn{2}{|c|}{6 month } & 1 year & \multicolumn{3}{|c|}{4 year } \\
\hline Mesh displacement & Nil & Nil & Nil & Nil & Nil & Nil \\
\hline Mesh infection & Nil & Nil & Nil & Nil & Nil & Nil \\
\hline Chronic port site infection & Nil & Nil & Nil & Nil & Nil & Nil \\
\hline Recurrence of hernia & Nil & Nil & Nil & Nil & Nil & Nil \\
\hline \multicolumn{7}{|l|}{ Patient satisfaction } \\
\hline Excellent & 55 & 55 & 65 & 65 & 98 & 98 \\
\hline Good & 19 & 19 & 18 & 18 & 02 & 02 \\
\hline Medium & 20 & 20 & 15 & 15 & Nil & Nil \\
\hline \multirow[t]{2}{*}{ Dissatisfactory } & 06 & 06 & 02 & 02 & Nil & Nil \\
\hline & & & Numbe & \multicolumn{3}{|c|}{ Percentage } \\
\hline \multicolumn{3}{|l|}{ Menopausal symptoms } & 35 & \multicolumn{3}{|c|}{35} \\
\hline \multicolumn{3}{|l|}{ Hormone replacement therapy } & 35 & \multicolumn{3}{|c|}{35} \\
\hline \multicolumn{3}{|c|}{ Tibolone for 6 months } & 10 & \multicolumn{3}{|c|}{10} \\
\hline \multicolumn{3}{|c|}{ Conjugated equine oestrogens for 3 months } & 25 & \multicolumn{3}{|c|}{25} \\
\hline
\end{tabular}

\section{DISCUSSION}

From January 2001 to December 2006, we were practising LH and LVHR in patients requiring both surgeries separately. Our experience made us realize that these two surgeries can be done in combination alleviating the need of multiple surgeries. Our learning curve for LH and other laparoscopic procedure had reached a satisfactory level in these years..$^{4-6}$ LH is a safe procedure. ${ }^{7}$ Combining two major surgeries may apparently lead to excessive pain, prolonged hospital stays, increased nausea, vomiting, paralytic ileus due to prolonged anaesthesia and increased risk of mesh infection. LVHR required average time of 40 minutes and hospital stay of 2 days which is comparable to Gillion et al who had average time of 43.4 minutes and 2.5day hospital stay. ${ }^{8}$ Despite 2 surgeries our patients had only mild pain by 7 th post-operative day Lipere et al also reported significant pain reduction by 8 th postoperative day. ${ }^{9}$ We had mild seroma formation in $50 \%$ cases which resolved with compression dressing only. Chelala et al eliminated the dead space by routine closure of the defect, thus reducing the seroma formation to $2.56 \%$ with low risk of infection $<1 \%{ }^{10}$ The development of a seroma is multifactorial and is likely related to the introduction of a foreign body eliciting an inflammatory response, as well as leaving the hernia sac intact.

The use of synthetic mesh for the repair of hernias has reduced recurrence rates significantly. But the use of synthetic mesh can be complicated by infection. The methods of sterilization and disinfection of laparoscopic instruments and mycobacterial infection constitute important causes for wound infection. The mesh infection rates range from 0.7 to $2 \%$ in LVHR. Our mesh infection rate was nil. We have used high level disinfection for fibreoptic cords and telescopes. Remaining all instruments were autoclaved. Mesh and tackers were never reused. We emphasize that we need to follow principles of surgery such as strict asepsis, meticulous haemostasis, delicate tissue handling and obliteration of dead spaces at hernia sites. Use of antibiotic impregnated drapes, preoperative and perioperative systemic antibiotic, topical application of antimicrobials and application of antibiotic releasing substances such as gentamycin releasing collagen tampons over the mesh have been used with variable success. ${ }^{11}$

The recurrence of hernia is an important issue. We have completed 4 years follow up for $100 \%$ cases with recurrence in none of the cases. We have operated $70 \%$ cases with defect size $3-5 \mathrm{cms}$ with overlap of mesh for 3$5 \mathrm{cms}$. Nardi et al found a $7 \%$ hernia recurrence at 5 years follow up. ${ }^{12}$ The factors related to the patient and the surgical technique that may influence the onset of early or late recurrence are a defect size $>5 \mathrm{~cm}$, an overlap of the mesh $<5 \mathrm{~cm}$, a BMI of $30 \mathrm{~kg} / \mathrm{m}^{2}$ or superior and the presence of significant comorbidities (ASA score 3) Leblance et al analysed 95 articles and found that the risk for recurrence of hernia decreased with increasing area of mesh overlap $(<3 \mathrm{~cm}$ incidence rate $0.086,3-5 \mathrm{~cm}$ incidence rate 0.046 and $>5 \mathrm{~cm}$ incidence rate 0.014$).{ }^{13}$

We had applied mesh in all cases even for small hernias $(1-3 \mathrm{~cm})$, Kaufman et al suggested that even for small hernias $(1-4 \mathrm{~cm})$ mesh repair should be the operation of choice. ${ }^{14}$ Choice of mesh can influence outcomes. ${ }^{15}$ From 2014 onwards we have been using symbotex composite mesh. Symbotex composite mesh is dual sided comprising of a microporous monofilament, hydrophilic textile in three-dimensional construction that allows for reinforced strength, memory shape and significant tissue in growth. A bioabsorbable collagen film on the visceral side minimizes tissue attachments. We had done defect closure in all cases. Danish nationwide cohort study showed a reduced risk of reoperation for recurrence if defect closure was performed in addition to mesh fixation during laparoscopic incisional hernia repair. ${ }^{16}$

We had combined LH and LVHR. While assessing patient satisfaction, we had put questions emphasising on menopausal symptoms, abdominal pain, vaginal discharge, sexual activity, capacity to do routine work and improvement in overall quality of life. Patient reported outcomes are $85 \%$ sensitive and $81 \%$ specific to detect recurrence. Patients reporting no bulge and no pain had $0 \%$ 
chance of recurrence. ${ }^{17,18}$ This is probably the only study combining LH with LVHR and adequate follow up of all cases for 4 years.

\section{Limitations}

Incisional hernia is an iatrogenic abdominal wall defect that occurs at the site of previous incision. Various factors have been identified to be responsible for the failure, including obesity, wound infection, suture material used for the closure of fascial defect, early wound infection and dehiscence. But we could not find detailed data on the factors that lead to hernia formation as no medical records were available with the patients. If these factors could have been found in our cohort, this study would have contributed on preventive aspects of hernia formation. Until techniques for the prevention of hernias are established, repair of these defects will remain an important topic of discussion.

This study has not analysed the cost benefit analysis of combining two major surgeries which should be definitely beneficial in terms of operative morbidity and reduction in disability days. The mean total cost for LVHR in France in 2011 was estimated to be 6451 Euros ranging from 4731 euros for unemployed patients to 10107 Euros for employed patients whose indirect costs (5375 Euros) were slightly higher than the direct costs. ${ }^{2}$

In our centre we are doing laparoscopic surgeries either LH or LVHR for last 20 years. Open surgeries are being done only in malignant cases or very large hernias requiring abdominal wall reconstruction. So, we are unable to give a comparable data between open and laparoscopic procedures for hysterectomy and ventral hernia repairs. Patient with incisional hernia and requirement of hysterectomy benefit substantially from surgery concerning quality of life independent of surgical technique. An event free recovery frequently occurred after laparoscopic surgery. ${ }^{19}$

LVHR is still an evolving surgery. In LVHR using a bridging technique, an overlap of at least $5 \mathrm{~cm}$ is not all that is required to prevent hernia recurrence. The ratio of mesh area to defect area (M/D ratio) is another important factor for recurrence. ${ }^{20} \mathrm{~A}$ ratio of 13 appears as the threshold under which that technique cannot be recommended and abdominal wall reconstruction may be required. We have not analysed M/D ratio in our study.

\section{CONCLUSION}

With advancements in minimal access surgery, combined laparoscopic procedures are now being performed for treating coexisting abdominal pathologies at the same surgery. We emphasize that LH can be easily done with LVHR. Since incisional hernias commonly occur after LSCS and for gynaecological problems, females always visit gynaecologist where we need to keep in mind that if patient needs hysterectomy and hernia repair, we can suggest these surgeries in combination reducing operative morbidity.

As long as the basic surgical principles, indications for combined procedures, meticulous exclusion criteria, strict asepsis are adhered to, minimal access surgery is feasible and appears to have several advantages in simultaneous management of two different coexisting pathologies with significant reduction in operative morbidity and hospital stay.

\section{Funding: No funding sources}

Conflict of interest: None declared

Ethical approval: The study was approved by the Institutional Ethics Committee

\section{REFERENCES}

1. Langbach O, Bukholm I, Benth JS, Rokke O. Longterm quality of life and functionality after ventral hernia mesh repair. Surg Endosc. 2016;30(11):502333.

2. Gillion JF, Sanders D, Miserez M, Muysoms F. The economic burden of incisional ventral hernia repair: a multicentric cost analysis. Hernia. 2016;20(6):819-30.

3. Shekhar C, Paswan B, Singh A. Prevalence, sociodemographic determinants and self-reported reasons for hysterectomy in India. Reprod Health. 2019;16(1):118.

4. Agrawal P, Agrawal R, Chandrakar J. Role of laparoscopy in vaginal hysterectomy for nonprolapsed uterus. J Obstet Gynecol India. 2007;57(2):151-4.

5. Agrawal P, Agrawal R, Chandrakar J. To Assess the safety of morcellation for removing uterine specimen during laparoscopic and vaginal hysterectomies for leiomyomas, J Obstet Gynecol India. 2016;66(S1):S567-72.

6. Agrawal P, Agrawal R, Chandrakar J. Prevention of vault prolapse in cases of procedentia using combined vaginal and laparoscopic approach for vault suspension: Agrawal's technique. Int J Reprod Contracept Obstet Gynecol. 2021;10(1):296-302.

7. Puntambekar S, Shetty STS, Goel A, Chandak S, Panchal S. Single-centre experience of doing safe total laparoscopic hysterectomy: retrospective analysis of 1200 cases, J Obstet Gynaecol India. 2020;70(5):376-83.

8. Gillion JF, Lepere M, Barrat C, Cas O, Dabrowski A, Jurczak F, et al. Two-year patient-related outcome measures (PROM) of primary, ventral and incisional hernia repair using a novel three-dimensional composite polyester monofilament mesh: the symchro registry study. Hernia. 2019;23:767-81.

9. Lepere M, Gillion JF, Barrat C, Cas O, Dabrowski A, Jurczak F, et al. First year preliminary results on the use of a monofilament polyester mesh with a collagen barrier for primary and incisional ventral hernia repair. Int Surg. 2018;103(1-2):56-65.

10. Chelala E, Baraké H, Estievenart J, Dessily M, Charara F, Allé JL, et al. Long-term outcomes of 1326 
laparoscopic incisional and ventral hernia repair with the routine suturing concept: a single institution experience. Hernia. 2016;20(1):101-10.

11. Narkhede R, Shah NM, Dalal PR, Mangukia C, Dholaria S. Postoperative mesh infection still a concern in laparoscopic era. Indian J Surg. 2015;77(4):322-6.

12. Nardi M, Millo P, Contul RB, Lorusso R, Usai A, Grivon M, et al. Laparoscopic ventral hernia repair with compositemesh: analysis of risk factors for recurrence in 185 patients with 5 years follow-up. Int J Surg. 2017;40:38-44.

13. Blanc K. Proper mesh overlap is a key determinant in hernia recurrence following laparoscopic ventral and incisional hernia repair. Hernia. 2016;20(1):85-99.

14. Kaufmann R, Halm JA, Eker HH, Klitsie PJ, Nieuwenhuizen J, Geldere DV, et al. Mesh versus suture repair of umbilical hernia in adults: a randomised, double-blind, controlled, multicentre trial. Lancet. 2018;391(10123):860-9.

15. Elango S, Perumalsamy S, Ramachandran K, Vadodaria K. Mesh materials and hernia repair. Biomed. 2017;7(3):16.

16. Baker JJ, Öberg S, Andresen K, Rosenberg J. Decreased re-operation rate for recurrence after defect closure in laparoscopic ventral hernia repair with a permanent tack fixated mesh: a nationwide cohort study. Hernia. 2018;22(4):577-84.

17. Baucom RB, Ousley J, Feurer ID, Beveridge GB, Pierce RA, Holzman MD, et al. Patient reported outcomes after incisional hernia repair-establishing the ventral hernia recurrence inventory. Am J Surg. 2016;212(1):81-8.

18. Bhanot P, Brenton R, Patel K. Proceed ${ }^{\mathrm{TM}}$ mesh for laparoscopic ventral hernia repair. JSLS. 2013;17:565-9.

19. Rogmark P, Petersson U, Bringman S, Ezra E, Österberg J, Montgomery A. Quality of life and surgical outcome 1 year after open and laparoscopic incisional hernia repair: prolove: a randomized controlled trial. Ann Surg. 2016;263(2):244-50.

20. Hauters P, Desmet J, Gherardi D, Dewaele S, Poilvache H, Malvaux P. Assessment of predictive factors for recurrence in laparoscopic ventral hernia repair using a bridging technique. Surg Endosc. 2017;31(9):3656-63.

Cite this article as: Agrawal P, Agrawal RK, Chandrakar J. Reducing operative morbidity among female patients combining laparoscopic hysterectomy and laparoscopic ventral hernia mesh repair procedures: a single centre 14 years experiences. Int J Reprod Contracept Obstet Gynecol 2021;10:2835-42. 